100. Ngoài ra, trên thực nghiệm còn thây tác dụng của LQTCT có tác dụng giảm IL-1 $\beta$, TNFa và PGE2 ở chuột, kéo dài thời gian sinh tồn của chuột trong điều kiên thiếu oxy, có tác dụng hồi phục suy tim trên thỏ, chống thiếu máu cơ tim, chống loạn nhịp tim trên động vật thực nghiệm[3]. Nghiền cứu trên thực nghiệm chứng minh Nhị trân thang có tác dụng hạ Cholesterol, Triglycerid, tăng NO, hạ ET [4], Thương truật có tác dụng kháng viêm, trấn tînh, lợi niệu [5]. Hoàng kỳ có tác dụng chống oxy hoá, hạ cholesterol và kháng viêm.

\section{KẾT LUẬN}

Viên nang LQTCT-NTT liều $0,28 \mathrm{~g} / \mathrm{kg} / \mathrm{ngày}$ và $0,56 \mathrm{~g} / \mathrm{kg} / \mathrm{ngày}$ có tác dụng tốt trong điều chỉnh rối loạn lipid máu ngoại sinh trên chuột cống trắng, làm giảm các chỉ số lipid máu gồm Cholesterol TP, LDL-Cholesterol, VLDL-Cholesterol, Triglyceride; giảm chỉ số Atherogenic; tăng HDL-
Cholesterol máu; giảm mõ bụng, giảm tình trạng nhiễm mõ gan. Các tác dụng này của LQTCTNTT tương đương với Atorvastatin liêu $10 \mathrm{mg} / \mathrm{kg} / \mathrm{ngày}$.

\section{TÀI LIÊU THAM KHẢO}

1. Hôi Tim mạch học Viêt Nam (2015), Khuyến cáo về chẩn đoán và điêuu trị rối loan Lipid máu của Hội Tim mach học Quốc gia Việt Nam 2015, Nhà xuất bản YY học, Hà Nội, 9-15.

2. Thanh Nguyễn Phương (2011), Nghiên cứu đôc tính và tác dụng điêu chinh rối loạn lipid máu của Monacholes trên thực nghiệm, Luận vằn Bác sĩ nội trú, Trường Đai hoc Y Hà Nôi.

3. Y. Yang, J. Qin, B. Ke, et al., (2013). "Effect of Linguizhugan decoction on hyperlipidemia rats with intermittent fasting", Journal of Traditional Chinese Medicine, vol. 33 , no. 2 , pp. $250-252$.

4. 刘秋琳。二陈汤降脂作用的理论探讨及实验研究。 山东中医药大学, 硕士学位论文摘要，2005年4月20号，18-25；

5.王本祥。现代中医药理与临床。天津科技翻译出本社 公司。2004年6月第一版，534，699，1367.

\title{
NGHIÊN CỨU NỒNG Độ SEROTONIN DICH NÃO TỦY VÀ MỐI LIÊN QUAN VớI MộT SỐ BIỂU HIỆN LÂM SÀNG Ở BÊ̂NH NHÂN MẮC BÊNNH PARKINSON
}

\author{
Trịnh Văn Quỳnh' ${ }^{1}$, Nhữ Đình Sơn ${ }^{1}$, Nguyễn Đức Thuận ${ }^{1}$, \\ Lê Văn Quân' ${ }^{1}$, Hoàng Thị Dung ${ }^{1}$, Nguyễn Hữu Quang ${ }^{2}$
}

\section{TÓM TẮT}

Mục tiêu: Nhận xét nồng độ serotonin dịch não tủy ở bênh nhân Parkinson và mối liên quan với lâm sàng. Đối tượng và phương pháp: Nghiên cứu tiến cứu, cắt ngang trên 61 bệnh nhân được chẩn đoán xác định bệnh Parkinson và 40 người khỏe manh tương đồng về tuổi, giới. Xét nghiệm đinh lượng nồng đô serortonin dịch não tủy cho cả nhóm bểnh và nhóm chứng. Kết quả: Tuổi trung bình nhóm bênh là $63,18 \pm 9,46$ tuổi, nhóm chứng là $61,77 \pm 9,53$ tuổi, khác biêt không có ý nghĩa thống kê với $p>0,05$. Nồng độ serotonin dịch não tủy trung bình nhóm bênh nhân Parkinson $(175,63 \pm 139,91 \mathrm{pg} / \mathrm{ml})$ giảm có ý nghĩa so với nhóm chứng $(398,60 \pm 267,93$ pg/ml) với $\mathrm{p}<0,001$; Giữa nồng đô serotonin dịch não tủy với thời gian mắc bệnh có mối tương quan nghịch với $r=$ 0,649, nồng độ serotonin dịch não tủy trung bình nhóm bệnh giảm dân theo mức độ năng của bệnh và giai đoạn bệnh, mức độ trầm cảm, nổng độ serotonin

${ }^{1}$ Bệnh viện Quân y 103

${ }^{2}$ Trường đại học Buôn Ma Thuôt

Chiu trách nhiệm chính: Trịnh Văn Quỳnh

Email: Trinhvanquynhhvqy@gmail.com

Ngày nhận bài: 10.3.2021

Ngày phản biện khoa học: 30.4.2021

Ngày duyệt bài: 12.5.2021 dịch não tủy trung bình nhóm bệnh nhân Parkinson có suy giảm nhận thức $(101,81 \pm 45,00 \mathrm{pg} / \mathrm{ml})$ giảm có ý nghĩa so với nhóm bệnh nhân Parkinson không có suy giảm nhân thức $(214,39 \pm 156,85 \mathrm{pg} / \mathrm{ml})$. Kết luân: Nghiên cứu chúng tôi cho thấy có sự giảm đáng kể nồng độ serotonin dich não tủy ở bệnh nhân Parkinson so với nhóm chứng, thời gian mắc bệnh càng lâu thì nồng độ serotonin dịch não tủy càng giảm, có sự giảm đáng kể nồng độ serotonin dịch não tủy ở bệnh nhân Parkinson có suy giảm nhận thức so với bệnh nhân Parkinson không có suy giảm nhận thức.

Từ khóa: Bệnh Parkinson; Nồng độ serotonin.

\section{SUMMARY}

RESEARCH OF CEREBROSPINAL FLUID CONCENTRATION OF SEROTONIN AND CORRELATION WITH SOME CLINICAL FEATURES AT PATIENTS WITH PARKINSON'S DISEASE

Objectives: To review the cerebrospinal fluid concentration of serotonin in patients with Parkinson's disease and its correlation with clinical features. Subjects and methods: A prospective, crosssectional study of 61 patients diagnosed with Parkinson's disease and 40 healthy people with the corresponding age, sex. Quantitative assay of cerebrospinal fluid serotonin concentration for patients 
group and controls group was done. Results: The mean age of the patient's group was $63.18 \pm 9.46$ years old; the control group was $61.77 \pm 9.53$ years old. There was no significant difference between the patient's group and the controls group with $p>0.05$. The mean of serotonin concentration in cerebrospinal fluid of Parkinson patients group (175.63 $139.91 \mathrm{pg} / \mathrm{ml}$ ) was significantly lower than that in the control group $(398.60 \pm 267.93 \mathrm{pg} / \mathrm{ml})$ with $\mathrm{p}<0.001$, there was a negative correlation between the cerebrospinal fluid serotonin concentration and duration of disease with correlated coefficients $r=-0.649$. The level of serotonin in cerebrospinal fluid in the patients group decreased gradually according to the level of disease, the stage of disease, the level of depression. The mean of serotonin concentration in cerebrospinal fluid of Parkinson patients group with cognitive impairment $(101.81 \pm 45.00 \mathrm{pg} / \mathrm{ml})$ was significantly lower than that in Parkinson patients group without cognitive impairment (214.39 $\pm 156.85 \mathrm{pg} / \mathrm{ml})$. Conclusion: Our study recognizes that decreased significantly cerebrospinal fluid serotonin levels of patients group and control group. The longer the duration of the disease was, the more the level cerebrospinal of serotonin decreased. It decreased significantly cerebrospinal fluid serotonin levels of Parkinson patients group with cognitive impairment and Parkinson patients group without cognitive impairment

Key words; Parkinson's disease; Serotonin concentration.

\section{I. ĐăT VẤN ĐỀ}

Bệnh Parkinson là bệnh thuộc nhóm bênh thoái hóa thần kinh tiến triển mạn tính thường gặp thứ 2 trên thế giới, sau bệnh Alzhemer's. Bệnh hay gặp ở người cao tuổi thường trên 50 tuổi, tỉ lệ mắc bệnh 1-2\% người trên 65 tuổi [1]. Đặc điểm bệnh lý quan trọng của bệnh Parkinson là mất các tế bào thần kinh thuộc hệ dopaminergic trong liềm đen. Hiện nay trên thể giới và trong nước có rất nhiều nghiên cứu về vai trò của các chất dẫn truyền thần kinh liên quan đến bệnh sinh của Parkinson ngoài hệ dopaminergic như: serotonin, GABA, glutamat, catecholamine... [2]. Một trong số đó có vai trò quan trọng trong bệnh sinh cũng như các triệu chứng rối loạn tâm thần ở bệnh nhân Parkinson đó là serotonin. Ngoài dopamin là chất dẫn truyền thần kinh đã được khẳng định trong bệnh sinh của Parkinson thì vai trò của serotonin trong bệnh Parkinson đang được tiếp tục nghiên cứu. Việc nghiên cứu nồng độ serotonin dịch não tủy ở bệnh nhân Parkinson đã được nhiều nghiên cứu trên thế giới đề cập. Tuy nhiên ở Việt Nam chưa có nghiên cứu nào đề cập đến việc định lượng và đánh giá sự thay đổi nồng độ serotonin dịch não tủy ở bệnh nhân Parkinson, vì vậy chúng tôi tiến hành nghiên cứu: "Nghiên cứu nồng độ serotonin dịch não tưy và mối liên quan với một số biểu hiện lâm sàng ở bệnh nhân mắc bênh Parkinson".

II. ĐỐI TƯợNG VÀ PHƯƠNG PHÁP NGHIÊN CỨU

2.1. Đối tượng nghiên cứu. 61 bệnh nhân nhóm bệnh được chẩn đoán bệnh Parkinson điều trị nội trú tại Khoa Thần kinh, Bệnh viện Quân y 103 từ tháng 9/2018 đến tháng 2/2021.

40 bệnh nhân nhóm chứng có tuổi, giới, trình độ học vấn tương đương nhóm nghiên cứu.

*Tiêu chuẩn lứa chọn nhóm bệnh:

- Nhóm bệnh được chẩn đoán bênh Parkinson theo tiêu chuẩn của Hội Ngân hàng Não và Parkinson Vương quốc Anh.

- Đồng ý tham gia nghiên cứu

*Tiêu chuấn loại trừ nhóm bênh:

- Bệnh nhân mắc hội chứng Parkinson.

- Bệnh Parkinson nhưng không biết chữ hoặc rối loạn chức năng ngôn ngữ như đọc, nghe.

- Không mắc bệnh hoặc dùng các thuốc ảnh hưởng đến nồng độ serotonin dịch não tủy.

- Bệnh nhân có rối loạn đông cầm máu

\subsection{Phương pháp nghiên cứu}

Tiến cứu, mô tả cắt ngang. Lựa chọn đối tượng theo tiêu chuẩn nghiên cứu. Đánh giá mức độ rối loạn vận động theo thang điểm thống nhất đánh giá bệnh Parkinson (UPDRSIII). Đánh giá giai đoạn bệnh theo Hoehn và Yahr. Đánh giá rối loạn trầm cảm theo thang điểm Beck. Đánh giá rối loạn nhận thức theo thang điểm MMSE.

*Phương pháp xét nghiệm mẫu: Định lượng nồng độ serotonin dịch não tủy dựa vào phương pháp sắc ký lỏng siêu hiệu năng 2 lần khối phổ UPLC/MS/MS tại Viện nghiên cứu $Y$ Dược học Quân sự, Học viện Quân y.

*Xử lý số liệu: bẳng phần mềm SPSS 20.0.

\section{KẾT QUẢ NGHIÊN CỨU VÀ BÀN LUẬN 3.1. Đặc điểm chung Bảng 1. Phân bố BN theo tuổi}

\begin{tabular}{|c|c|c|c|c|}
\hline \multirow{2}{*}{ Tuổi (năm) } & \multicolumn{2}{|c|}{ Nhóm bệnh } & \multicolumn{2}{|c|}{ Nhóm chứng } \\
\hline & Số BN & Tỉ lệ \% & Số BN & Tỉ lệ \% \\
\hline Dưới 40 & 1 & 1,6 & 0 & 0 \\
\hline $\begin{array}{c}\text { Từ 40-49 } \\
\text { tuổi }\end{array}$ & 5 & 8,2 & 3 & 7,5 \\
\hline $\begin{array}{c}\text { Từ 50-59 } \\
\text { tuổi }\end{array}$ & 15 & 24,6 & 11 & 27,5 \\
\hline $\begin{array}{c}\text { Từ 60-69 } \\
\text { tuổi }\end{array}$ & 24 & 39,3 & 18 & 45,0 \\
\hline$\geq 70$ tuối & 16 & 26,3 & 8 & 20,0 \\
\hline Tổng & 61 & 100 & 40 & 100 \\
\hline $\begin{array}{c}\text { Tuối trung } \\
\text { bình }\end{array}$ & \multirow{2}{*}{\multicolumn{2}{|c|}{$\begin{array}{c}63,18 \pm \\
9,46\end{array}$}} & \multicolumn{2}{|c|}{$\begin{array}{c}61,77 \pm \\
9,53\end{array}$} \\
\hline $\mathrm{p}$ & & & 05 & \\
\hline
\end{tabular}


90,2\% BN Parkinson từ 50 tuổi trở lên, trong đó BN từ 60-69 tuổi chiếm 39,3\%. Tuổi trung bình nhóm bệnh là $63,18 \pm 9,46$ tuổi, nhóm chứng là $61,77 \pm 9,53$ tuổi, khác biệt không có ý nghĩa thống kê với $p>0,05$. Kết quả nghiên cứu của chúng tôi phù hợp với các báo cáo trước đây của các tác giả trong nước và quốc tế. Theo Pagano và cộng sự (2016) tuổi khởi phát trung bình của bệnh nhân Parkinson là $61,6 \pm 9,73$ tuổi, với bệnh nhân có độ tuổi từ 60-90 chiếm tỷ lệ cao nhất $164 / 414=39,81 \%$ [3]. Kết quả này cũng phù hợp với tuổi trung bình nhóm bệnh Parkinson trong nghiên cứu của Nguyễn Bá Nam $(62,6 \pm 8,78$ tuổi) [4].

3.2. Kêt quả nghiên cứu nồng độ serotonin dịch não và mối liên quan với lâm sàng

*Nông độ serotonin dịch não tủy nhóm nghiên cứu

Bảng 2. Nồng độ serotonin dịch não tủy ở các nhóm nghiên cứu

\begin{tabular}{|c|c|c|}
\hline $\begin{array}{l}\text { Nhóm } \\
\text { nghiên cứu }\end{array}$ & $\begin{array}{l}\text { Khoảng } \\
\text { dao động } \\
\text { (pg/ml) }\end{array}$ & $\begin{array}{c}\text { Giá trị trung } \\
\text { bình }(X \pm S D) \\
(\mathrm{pg} / \mathrm{ml})\end{array}$ \\
\hline $\begin{array}{l}\text { Nhóm bêenh } \\
(\mathrm{n}=61)\end{array}$ & $\begin{array}{l}50,42 \div \\
749,21\end{array}$ & $\begin{array}{c}175,63 \pm \\
139,91 \\
\end{array}$ \\
\hline $\begin{array}{l}\text { Nhóm chứng } \\
(\mathrm{n}=40)\end{array}$ & $\begin{array}{l}176,27 \div \\
1399,62\end{array}$ & $\begin{array}{c}398,60 \\
\pm 267,93 \\
\end{array}$ \\
\hline$p$ & \multicolumn{2}{|c|}{$\mathrm{P}<0,001$} \\
\hline
\end{tabular}

Nồng độ serotonin dịch não tủy ở nhóm bệnh nhân Parkinson dao động từ 50,42 749,21 $\mathrm{pg} / \mathrm{ml}$ với giá trị trung bình là $175,63 \pm 139,91$ $\mathrm{pg} / \mathrm{ml}$ trong khi ở nhóm người khỏe mạnh nồng độ serotonin dịch não tủy dao động từ 176,27 : $1399,62 \mathrm{pg} / \mathrm{ml}$ với giá trị trung bình là 398,60 \pm $267,93 \mathrm{pg} / \mathrm{ml}$. Thống kê bằng phương pháp student-t test với 2 chuỗi số độc lập cho thấy nồng độ serotonin dịch não tủy ở nhóm bệnh nhân Parkinson thấp hơn có ý nghĩa thống kề so với nhóm chứng $(p<0,001)$.

So sánh với nồng độ serotonin dịch não tủy ở nhóm chứng, chúng tôi thấy rằng nồng độ serotonin dịch não tủy giảm trên bệnh nhân Parkinson với sự khác biệt có ý nghĩa thống kê. Kết quả nghiên cứu của chúng tôi phù hợp với sự thay đổi nồng độ serotonin dịch não tủy trên bệnh nhân Parkinson. Sự giảm nồng độ serotonin dịch não tủy đã được ghi nhận ở các nghiên cứu Johansson và cộng sự (1971) [5]và gần đây là nghiên cứu của Olivola và cộng sự (2014) [6]. Như vậy, mặc dù số nghiên cứu liên quan đến sự biến đổi nồng độ serotonin dịch não tủy trên bệnh nhân Parkinson còn tương đối hạn chế nhưng các nghiên cứu đều đi đến kết luận có mối tương quan giữa sự thay đổi về nồng độ serotonião tủy dịch nvới bệnh Parkinson ở mức độ nào đó.

*Mối tương quan giữa nồng độ serotonin dịch não tủy với thời gian mắc bệnh

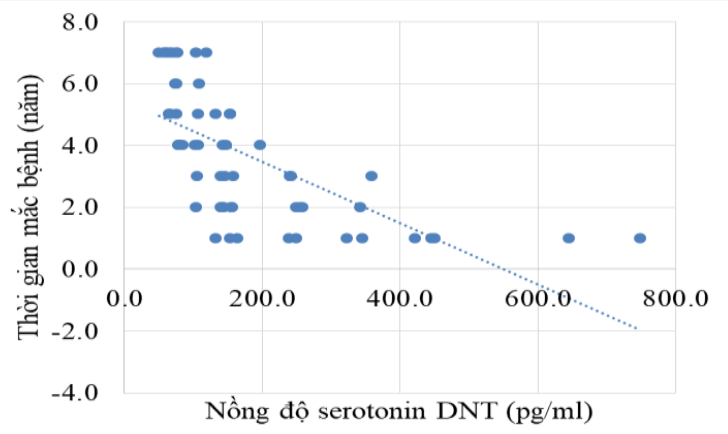

Biểu đồ 1. Tương quan nồng độ serotonin dịch não tủy và thời gian mắc bệnh

Sử dụng phương pháp phân tích tướng quan hồi qui tuyến tính cho thấy nồng độ serotonin dịch não tủy tương quan nghịch có ý nghĩa thống kê với thời gian bị bệnh $(r=-0,649$, $p<0,001$ với dịch não tủy). Kêt quả này cho thây rằng thời gian bị bệnh càng lâu, nồng độ serotonin dịch não tủy càng giảm.

Trong nghiên cứu này chúng tôi thây rằng có mối tương quan nghịch giữa nồng độ serotonin dịch não tủy với thời gian bị bệnh. Chú ý rằng Parkinson là bệnh thoái hóa thần kinh tiến triển, bệnh nặng dần theo thời gian bị bệnh. Thoái hóa thần kinh trung ương có thể dẫn đến rối loạn hoạt động của các hệ thống chất dẫn truyền thần kinh trung ương, đặc biệt là hệ dopamine và serotonin. Do đó, cơ sở trển đây là phù hợp với kết quả nghiên cứu của chúng tôi cho thấy nồng độ serotonin dịch não tủy giảm dần theo thời gian bị bệnh trên bệnh nhân Parkinson.

*Mối liên quan giữa nồng độ serotonin dịch não tủy với mức độ bệnh

Bảng 3. Nồng độ serotonin dịch não tủy theo mức độ bệnh

\begin{tabular}{|c|c|}
\hline Mức độ bệnh & Serotonin DNT(pg/ml) \\
\hline Nhẹ $(1)(n=27)$ & $279,64 \pm 154,68$ \\
\hline Vưa $(2)(n=16)$ & $118,39 \pm 21,20$ \\
\hline $\begin{array}{c}\text { Nặng và rất nă̆ng } \\
\text { (3) }(n=18)\end{array}$ & $70,49 \pm 11,56$ \\
\hline$p$ & $P 3,2-1<0,001$ \\
\hline
\end{tabular}

Nồng độ serotonin dịch não tủy giảm dần từ mức độ bệnh nhẹ đến mức độ nặng và rất nặng. Thống kê cho thấy nồng độ serotonin dịch não tủy ở nhóm bệnh nặng và rất nặng và nhóm bệnh nhân bị bệnh mức độ vừa thấp hơn có ý nghĩa thống kê so với nhóm bệnh nhân bị bệnh 
nhẹ $(p<0,001)$.

* Mối liên quan giữa nồng độ serotonin dịch não tủy với giai đoạn bệnh

Bảng 4. Môí liên quan nồng độ serotonin dịch não tưy với giai đoạn bệnh

\begin{tabular}{|c|c|}
\hline Giai đoạn bệnh & $\begin{array}{c}\text { Serotonin DNT } \\
(\mathbf{p g} / \mathbf{m l})\end{array}$ \\
\hline Giai đoạn 1 $(1)(n=17)$ & $325,35 \pm 174,56$ \\
\hline Giai đoạn 2 (2) $(n=21)$ & $154,84 \pm 66,71$ \\
\hline Giai đoạn 3 (3) $(n=17)$ & $90,17 \pm 25,37$ \\
\hline $\begin{array}{c}\text { Giai đoạn 4 và 5 (4) } \\
(n=6)\end{array}$ & $66,32 \pm 18,70$ \\
\hline$p$ & $P 1-2,3,4<0,001$ \\
\hline
\end{tabular}

Nồng độ serotonin dịch não tủy giảm dần theo giai đoạn bệnh, từ giai đoạn 1 đến giai đoạn 4 và 5 . Thống kê cho thấy nồng độ serotonin dịch não tủy ở các nhóm bệnh nhân giai đoạn 2 , giai đoạn 3 và giai đoạn 4 và 5 thấp hơn có ý nghĩa thống kê so với nhóm bệnh nhân ở giai đoạn $1(p<0,001)$.

Tương tự với thời gian mắc bệnh, trên bệnh nhân Parkinson, chúng tôi cũng thấy nồng độ serotonin dịch não tủy giảm dần theo mức độ bênh, từ mức độ nhe đến mức độ nặng, cũng như theo giai đoạn bệnh, từ giai đoạn 1 đến giai đoạn 5. Trên các nghiên cứu hình ảnh cho thây có sự giảm thể tích các cấu trúc vỏ não và dưới vỏ theo mức độ và giai đoạn của bệnh [7], [8]. Sự giảm thể tích các cấu trúc này có thể dẫn đến sự giảm hoạt của hệ thống serotonin trên hệ thần kinh trung ương, mà phản ảnh trực tiếp là nồng độ serotonin dịch não tủy trên bệnh nhân Parkinson. Hơn nữa, chúng tôi cũng cho rằng mức độ bệnh nặng hơn với các giai đoạn bệnh muộn hơn thì các rối loạn nội sinh cũng tăng lên trên bệnh nhân Parkinson. Kết quả dẫn đến nồng độ serotonin dịch não tủy sẽ giảm dần theo mức độ và giai đoạn bệnh trên bệnh nhân Parkinson.

*Mối liên quan giữa nồng độ serotonin dịch não tủy với trâm cảm

Bảng 5. Môi liên quan giữa serotonin với trầm cảm

\begin{tabular}{|c|c|}
\hline Mức độ trâm cảm & $\begin{array}{c}\text { Nồng độ } \\
\text { Serotonin ḊNT } \\
(\mathbf{p g} / \mathbf{m l})\end{array}$ \\
\hline $\begin{array}{c}\text { Không có trầm cảm }(1) \\
(\mathrm{n}=27)\end{array}$ & $255,17 \pm 168,72$ \\
\hline Trầm cảm nhẹ $(2)(\mathrm{n}=14)$ & $128,24 \pm 67,81$ \\
\hline Trầm cảm vừa $(3)(\mathrm{n}=11)$ & $107,87 \pm 69,56$ \\
\hline Trầm cảm nặng $(4)(\mathrm{n}=9)$ & $93,55 \pm 40.02$ \\
\hline$p$ & $\mathrm{P} 1-2,3,4<0,05$ \\
\hline
\end{tabular}

Nồng độ serotonin dịch não tủy giảm dần từ không bị trầm cảm đến trầm cảm mức độ nhẹ, vừa và nặng. Thống kê cho thấy nồng độ serotonin dịch não tủy ở các nhóm bệnh nhân trầm cảm thấp hơn có ý nghĩa thống kê so với nhóm bệnh nhân không bị trầm cảm $(p<0,05)$.

* Mối liên quan giữa nồng độ serotonin dịch não tủy với rối loạn nhận thức

Bảng 6. Môi liên giữa serotonin với rôi loan nhân thức

\begin{tabular}{|c|c|}
\hline $\begin{array}{c}\text { Suy giảm nhận } \\
\text { thức }\end{array}$ & $\begin{array}{c}\text { Serotonin DNT } \\
\mathbf{( p g} / \mathbf{m l})\end{array}$ \\
\hline Có $(\mathrm{n}=21)$ & $101,81 \pm 45,00$ \\
\hline Không có $(\mathrm{n}=40)$ & $214,39 \pm 156,85$ \\
\hline $\mathrm{p}$ & $\mathrm{P}<0,01$ \\
\hline
\end{tabular}

Nồng độ serotonin dịch não tủy ở nhóm bệnh nhân có suy giảm nhận thức thấp hơn có ý nghĩa thống kê so với nhóm bệnh nhân không có suy giảm nhận thức $(p<0,01)$.

Trên bênh nhân Parkinson ngoài các triệu chứng vận động là triệu chứng chính thì cũng thường có các triệu chứng ngoài vận động như trầm cảm, rối loạn nhận thức, rối loạn trí nhớ ... Vì vậy, phân tích mối liên quan giữa nồng độ serotonin với các triệu chứng ngoài vận động trên bệnh nhân Parkinson cũng hết sức cần thiết. Kết quả nghiên cứu cho thấy nồng độ serotonin dịch não tủy giảm dần từ nhóm bệnh nhân không bị trầm cảm đến nhóm bênh nhân trầm cảm mức độ nhe rồi bênh nhân trầm cảm mức độ vừa và thấp nhất là nhóm bệnh nhân trầm cảm mức độ nặng. Thống kê cho thấy nồng đô serotonin dịch não tủy ở các nhóm bênh nhân trầm cảm thấp hơn có ý nghĩa thống kề so với ở nhóm bệnh nhân không có trầm cảm. Đặc biệt, kết quả của chúng tôi còn cho thấy nồng độ serotonin dịch não tủy ở nhóm bệnh nhân trầm cảm mức đồ nă̆ng thấp hơn có ý nghĩa thống kê so với ở nhóm bệnh nhân trầm cảm mức độ nhẹ. Kết quả nghiên cứu của chúng tôi phù hợp với các kết quả nghiên cứu trước đây về mối liên quan giữa hoạt đông của hê thống chất dẫn truyền thần kinh với trầm cảm trên bệnh nhân Parkinson. Trên các nghiên cứu hình ảnh với chất đánh dấu cho thấy sự giảm hoạt động của hệ thống serotoninergic ở một số vùng của não như vùng nhân vách, thùy trán, vùng dưới đồi trên bệnh nhân trầm cảm so với người khỏe manh. Sự giảm hoạt động này có thể làm nguyên nhân dẫn đến sự giảm nồng đô serotonin trong dịch não tủy như ghi nhận từ nghiên cứu của chúng tôi cũng như các nghiên cứu trước đây. Tan và cộng sự (2011) cũng chứng minh được rằng nồng độ serotonin trong dịch não tủy giảm trên bệnh nhân Parkinson có trầm cảm. Tuy nhiên, cũng có một số ít nghiên 
cứu cho thấy sự giảm nồng độ serotonin trong dịch não tủy là không có tương quan với trâm cảm trên bệnh nhân Parkinson [6]. Vì vậy, cần có những nghiên cứu với cõ̃ mẫu lớn hơn để xác định vấn đề này.

Hoạt động của hệ thống serotonin có liên quan chặt chẽ đến chức năng nhận thức và trí nhớ. Vì vậy, sự suy giảm các chức năng này có thể tương quan với sư giảm hoat động của hê thống serotonin trên bệnh nhân Parkinson, mà biểu hiện bằng sự giảm nồng độ của serotonin trong dich não tủy. Kết quả nghiên cứu của chúng tôi cho thấy nồng độ serotonin trong dịch não tủy ở nhóm bệnh nhân có suy giảm suy giảm nhận thức là thấp hơn có ý nghĩa thống kê so với ở nhóm bệnh nhân Parkinson không có suy giảm nhận thức. Kết quả này cùng với các kết quả trên đây đã cho thấy sự mối liên quan rõ rệt giữa sự thay đổi nồng độ serotonin trong dịch não tủy với các triệu chứng vận động cũng như các triệu chứng ngoài vận động trên bệnh nhân Parkinson.

\section{KẾT LUẬN}

Tuổi trung bình nhóm bệnh nhân Parkinson là 63,18 \pm 9,46 tuổi , 90,2\% bệnh nhân Parkinson từ 50 tuối trở lên, trong đó BN từ 60-69 tuổi chiếm 39,3\%. Nồng độ trung bình serotonin dịch não tủy ở nhóm bệnh giảm có ý nghĩa so với nồng độ serotonin dịch não tủy nhóm chứng. Giữa nồng độ serotonin dịch não tủy với thời gian mắc bệnh có mối tương quan nghịch với $r=-$ $0,649, p<0,001$. Nồng độ serotonin dịch não tủy trung bình nhóm bệnh giảm dần theo mức độ nặng của bệnh và giai đoạn bệnh, trầm cảm. Nồng độ serotonin dịch não tủy trung bình bệnh nhân Parkinson có suy giảm nhận thức giảm có ý nghĩa so với bệnh nhân Parkinson không có suy giảm nhận thức.

\section{TÀI LIỆ THAM KHẢO}

1. Chuquilin-Arista, F., T. Alvarez-Avellon, and M. Menendez-Gonzalez (2019), Prevalence of Depression and Anxiety in Parkinson Disease and Impact on Quality of Life: A Community-Based Study in Spain. J Geriatr Psychiatry Neurol, p. 891988719874130.

2. Politis, M. and C. Loane (2011), Serotonergic dysfunction in Parkinson's disease and its relevance to disability. ScientificWorldJournal, 11: p. 1726-34.

3. Pagano, G., et al. (2016), Age at onset and Parkinson disease phenotype. Neurology, 86(15): p. $1400-1407$.

4. Nguyễn Bá Nam (2016), Nghiên cứu đặc điểm lâm sàng và nồng độ homocysteine huyết tương ở bệnh nhân mắc bệnh Parkinson, Học viện Quân y.

5. Johansson, B. and B.E. Roos (1971), 5Hydroxyindoleacetic acid in cerebrospinal fluid of patients with Parkinson's syndrome treated with LDOPA. European Journal of Clinical Pharmacology, 3(4): p. 232-235.

6. Olivola, E., et al.(2014), Serotonin impairment in CSF of PD patients, without an apparent clinical counterpart. PLoS One, 9(7): p. e101763.

7. Zarei, M., et al. (2013), Cortical thinning is associated with disease stages and dementia in Parkinson's disease. J Neurol Neurosurg Psychiatry,84(8): p. 875-81.

8. Wilson, H., et al.(2019), Cortical thinning across Parkinson's disease stages and clinical correlates. J Neurol Sci, 398: p. 31-38.

\section{KẾT QUẢ SẢN KHOA Ở THAI PHỤ ĐÁI THÁO ĐƯờNG THAI KỲ ĐÊ ĐỦ THÁNG TẠI BỆNH VIỆN PHỤ SẢN TRUNG ƯO'NG}

\section{TÓM TẮT}

Muc tiêu: nhân xét kết quả sản khoa ở thai phu đái tháo đường thai kỳ đẻ đủ tháng tại Bệnh viện Phụ sản Trung ương năm 2019-2020.Kêt quả: tỷ lệ bệnh nhân ĐTĐTK mổ đẻ $(78,29 \%)$ cao hơn so với tỷ lệ đẻ thường. Các nguyên nhân ĐTĐTK đẻ mổ thường gặp là do nguyên nhân có tiền sử mổ cũ $(32,03 \%)$, nguyên nhân do thai to chiếm 14,84\%.Cân nặng sơ

\footnotetext{
*Trường Đại học Y Hà Nọi

Chịu trách nhiệm chính: Nguyễn Mạnh Thắng

Email: bsnguyenmanhthang@gmail.com

Ngày nhận bài: 8.3.2021

Ngày phản biên khoa học: 29.4.2021

Ngày duyệt bài: 11.5.2021
}

Nguyễn Mạnh Thắng* sinh trung bình của nhóm thai phụ ĐTĐTK đẻ đủ tháng là $3433 \pm 442 \mathrm{~g}$. Có 12 trẻ có cân năng từ $4000 \mathrm{~g}$ trở lên, chiếm $7,05 \%$. Phần lớn trẻ sinh ra có me bị ĐTĐTK không có biến chứng sau đẻ, chiếm tỷ lê $81,64 \%$. Có 4 trẻ bị hạ glucose máu $(2,35 \%), 22$ trẻ có bị vàng da sau sinh $(12,94 \%)$. Tỷ lệ trẻ sơ sinh có chỉ số Apgar sau 1 phút và sau 5 phút $<7$ điểm chiếm tỷ lệ thấp (lần lượt là 2,94\% và 1,18\%). Kết luận: thai phụ ĐTĐTK có tỷ lệ mổ đẻ cao. Biến chứng ở trẻ sinh ra có me bị ĐTĐTK thường gặp là vàng da sau sinh, biến chứng ít gặp hơn là hạ glucose máu và suy hô hấp sau sinh.

Tư khoá: kết quả sản khoa, đái tháo đường thai kỳ, hạ đường máu, suy hô hấp sau sinh, vành da sau sinh.

\section{SUMMARY \\ MATERNAL AND FETAL OUTCOME IN}

